\title{
Brevibacterium casei
}

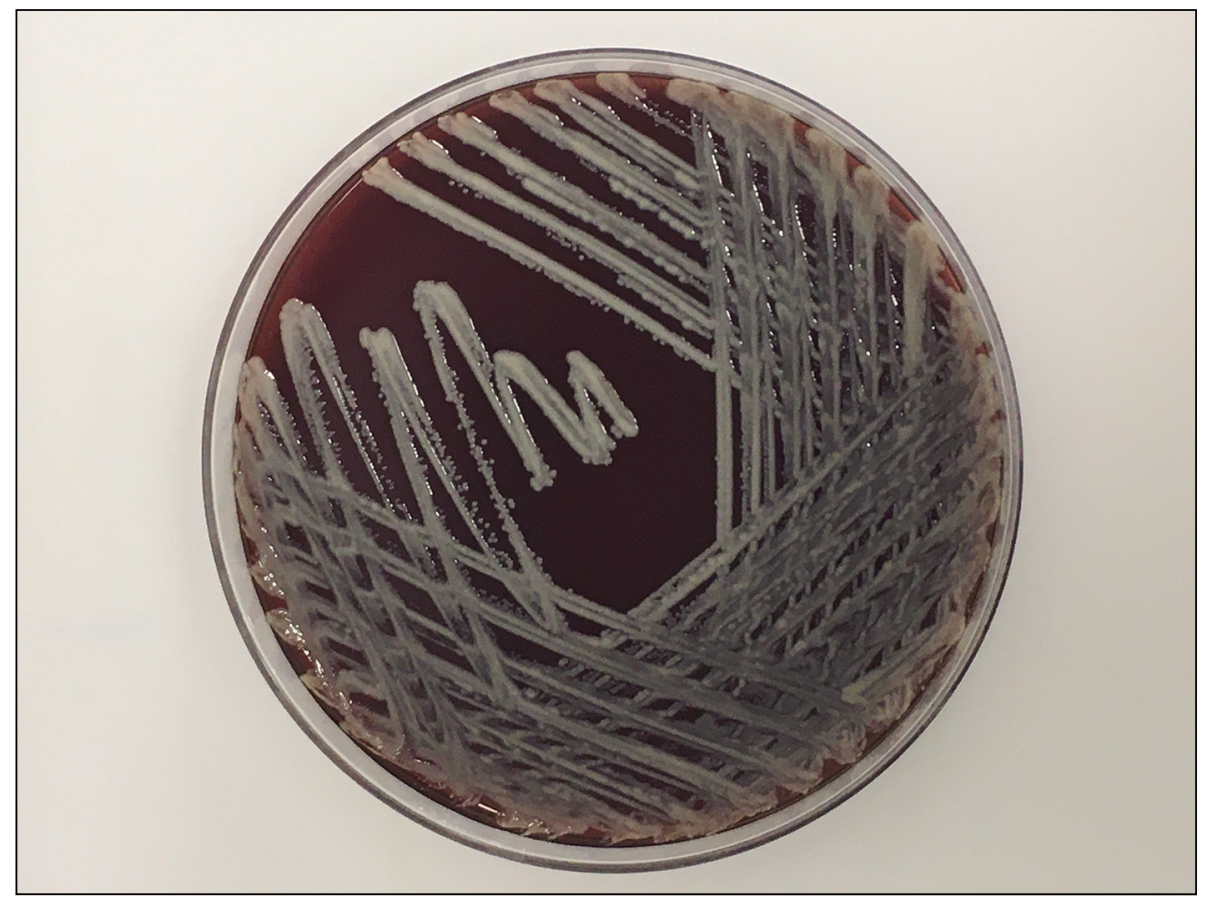

Figura 1. Colonias de Brevibacterium casei en agar sangre de cordero $5 \%$.

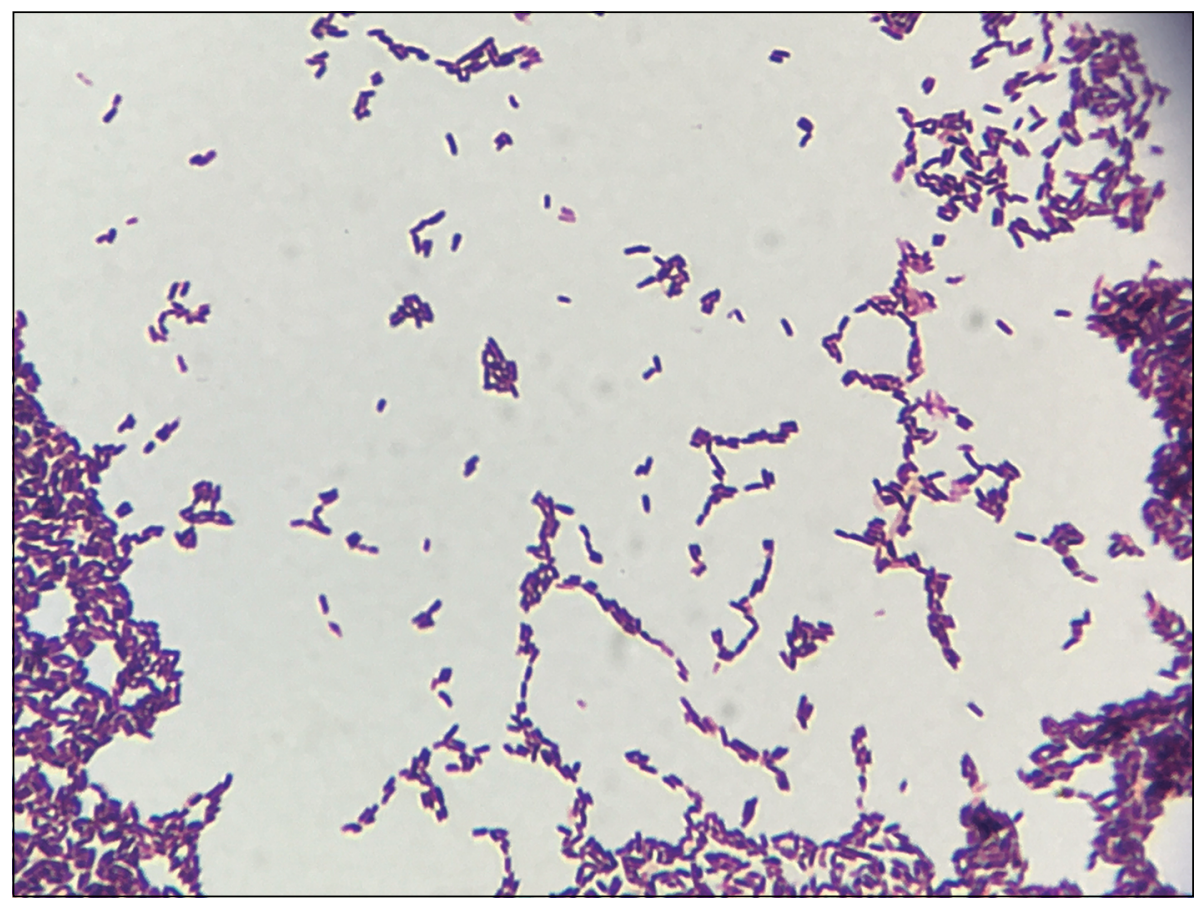

Figura 2. Bacilos grampositivos pequeños dispuestos en empalizada. Tinción de Gram. 100X. 


\section{Brevibacterium casei}

Brevibacterium casei es una bacteria corineforme perteneciente al género Brevibacterium. Este género está compuesto por 45 especies diferentes, de las cuales sólo 10 han sido aisladas de muestras clínicas, incluyendo a $B$. casei. Es un bacilo grampositivo, aeróbico, catalasa positiva, halotolerante, con crecimiento óptimo entre $30^{\circ}$ y $37^{\circ} \mathrm{C}$ e inmóvil. Es considerado parte de la microbiota normal de la piel y excepcionalmente como causa de patología en humanos. Se ha descrito como agente causal en casos de meningitis, abscesos cerebrales, endocarditis, peritonitis y sepsis asociadas a dispositivos vasculares. Dada su capacidad de producir biopelículas, $B$. casei podría ser considerado un microorganismo particularmente patógeno en pacientes con catéteres vasculares y con inmunosupresión. Por otro lado, se encuentra presente en fuentes animales como la leche cruda y el queso, contribuyendo notablemente a su aroma característico y color anaranjado de su superficie.

En cuanto a sus características microbiológicas, $B$. casei puede ser recuperado desde muestras de hemocultivos y otros líquidos biológicos en medios como agar sangre de cordero y en condiciones aeróbicas y/o microaerofilia. Macroscópicamente, las colonias son pequeñas, lisas, de color gris claro y con aspecto brillante (Figura 1). Además, presentan consistencia levemente mucosa al ser tomadas con asa, similar a lo encontrado en microorganismos formadores de biopelículas. De forma característica, tienen un marcado olor a queso. Microscópicamente, se observan bacilos grampositivos pequeños, agrupados en empalizadas (Figura 2). La identificación a nivel de especie se puede realizar mediante pruebas fenotípicas con baterías bioquímicas específicas, análisis de ácidos grasos o genotipificación. Sin embargo, actualmente la metodología más utilizada para la identificación de este microorganismo es la espectrometría de masas MALDI-TOF, ya que ha demostrado ser confiable y rápida.

Finalmente, en cuanto al perfil de susceptibilidad antimicrobiana, B. casei podría demostrar resistencia a $\beta$-lactámicos y clindamicina, pero la mayoría de las cepas aún son susceptibles a glicopéptidos como vancomicina, lo que justifica su uso como terapia de primera línea. No obstante, existen casos descritos que evidencian que vancomicina intravenosa puede no ser suficiente para erradicar la colonización del catéter y que puede persistir incluso cuando los hemocultivos se hacen negativos. Por lo tanto, se prefiere la remoción del dispositivo o la terapia intravenosa de vancomicina combinada con terapia antibacteriana de bloqueo (lock therapy) vía catéter.

\section{Referencias bibliográficas}

1.- Brazzola P, Zbinden R, Rudin C, Schaad U B, Heininger U. Brevibacterium casei sepsis in an 18-year-old female with AIDS. J Clin Microbiol. 2000; 38: 3513-4. doi: 10.1128/JCM.38.9.3513-3514.2000.

2.- Beukinga I, Rodríguez-Villalobos H, Deplano A, Jacobs F, Struelens M J. Management of long-term catheter-related Brevibacterium bacteraemia. Clin Microbiol Infect. 2004; 10: 465-7. doi: 10.1111/j.1469-0691.2004.00857.x.

3.- Bal Z S, Sen S, Karapinar D Y, Aydemir S, Vardar F. The first reported catheter-related Brevibacterium casei bloodstream infection in a child with acute leukemia and review of the literature. Braz J Infect Dis. 2015; 19: 213-5. doi:10.1016/j.bjid.2014.09.011.

Carolina Alarcón', Belén González', Angie Henríquez ${ }^{1}$ y Claudia Ramírez ${ }^{1}$ ${ }^{1}$ Laboratorio Hospital Dr. Exequiel González Cortés. 